Association for Information Systems

AIS Electronic Library (AISeL)

ICEB 2009 Proceedings

International Conference on Electronic Business

(ICEB)

Winter 12-4-2009

Revenue Sharing with Multiple Airlines and Airports

Anming Zhang

Xiaowen Fu

Hangjun (Gavin) Yang

Follow this and additional works at: https://aisel.aisnet.org/iceb2009

This material is brought to you by the International Conference on Electronic Business (ICEB) at AIS Electronic Library (AISeL). It has been accepted for inclusion in ICEB 2009 Proceedings by an authorized administrator of AIS Electronic Library (AISeL). For more information, please contact elibrary@aisnet.org. 


\title{
REVENUE SHARING WITH MULTIPLE AIRLINES AND AIRPORTS
}

\author{
Anming Zhang ${ }^{1}$, Xiaowen $\mathrm{Fu}^{2}$, and Hangjun (Gavin) Yang ${ }^{3}$ \\ ${ }^{1}$ Sauder School of Business, University of British Columbia, 2053 Main Mall, Vancouver, BC, \\ Canada V6T 1 Z2 \\ ${ }^{2}$ Faculty of Business, Hong Kong Polytechnic University, Hong Kong \\ ${ }^{3}$ Sauder School of Business, University of British Columbia, 2053 Main Mall, Vancouver, BC, \\ Canada V6T $1 Z 2$ \\ anming.zhang@sauder.ubc.ca, lgtxfu@polyu.edu.hk, gavin.yang@sauder.ubc.ca
}

\begin{abstract}
This paper investigates the effects of concession revenue sharing between an airport and its airlines. It is found that the degree of revenue sharing will be affected by how carriers' services are related (complements, independent, or substitutes). In particular, when carriers provide substitutable services, the sharing proportions might become negative if horizontal substitutability is sufficiently strong. In these situations, while revenue sharing improves profit, it reduces social welfare. It is further found that airport competition results in a higher degree of revenue sharing than would be had in the case of single airports. Nevertheless, the airport-airline chains may derive lower profits through this revenue-sharing rivalry, and the situation is similar to a classic Prisoners' Dilemma. As the airport-airline chains move further away from their joint profit maximum, social welfare rises beyond the level achievable by single airports. Our analysis also shows that the (equilibrium) revenue-sharing proportion at an airport decreases in the number of its carriers, and increases in the number of carriers at the competing airports. Finally, the effects of the pure sharing contract are compared with those of the two-part sharing contract.
\end{abstract}

Keywords: Concession revenues; Revenue sharing; Airport competition; Airport-airline vertical cooperation; Non-atomistic carriers

Acknowledgement: Financial support from the Hong Kong Competitive Earmarked Research Grant (RGC-PolyU5412/07H) and the Social Science and Humanities Research Council of Canada (SSHRC) are gratefully acknowledged.

\section{Introduction}

An airport derives revenue from two facets of business: the traditional aeronautical operations and the commercial (concession) operations. The former refer to aviation activities associated with runways, aircraft parking and terminals, whereas the latter refer to non-aeronautical activities occurring within terminals and on airport land, including terminal concessions, and car parking and rental. For the last two decades, commercial revenues have grown faster than aeronautical revenues; as a result, they become the main income source of many airports. At medium to large US airports, for instance, commercial business represents $75-80 \%$ of the total airport revenue (Doganis, 1992). ATRS (2008) studied 142 airports worldwide and found a majority of these airports derived $40-75 \%$ of their total revenues from non-aviation services, a major part of which is revenue from concession services (with large hub airports relying, on average, even more on concession income). Furthermore, commercial operations tend to be more profitable than aeronautical operations (e.g., Jones et al., 1993; Starkie, 2001; Francis et al., 2004), owing partly to prevailing regulations and charging mechanisms (e.g., Starkie, 2001).

Paralleling the growth of concession revenues, revenue sharing between airports and airlines is getting popular in practice. As documented in Fu and Zhang (2009), there are cases, such as Tampa International Airport in the US and Ryanair in Europe, where airports and airlines share concession revenues. 1 In many other cases, revenue sharing is in effect when airports allow airlines to hold shares or directly control airport facilities. For example, Terminal 2 of Munich airport was jointly invested by the airport operating company FMG (60\%) and Lufthansa (40\%), which is the airport's dominant carrier (Kuchinke and Sickmann, 2005). Commercial profits generated from this terminal are thus shared between FMG and Lufthansa. Fu and Zhang (2009) found that concession revenue sharing has important competitive and welfare implications: it allows the airport and airlines to internalize a multi-output

\footnotetext{
1 Tampa International Airport has been sharing revenue with its carriers for several years. In 2004, it shared \$7 million out of a total budget of $\$ 30$ million (see the 2004 Annual Report of Tampa International Airport). On the other hand, Ryanair has identified airport car parking as one of its business opportunities and cooperated with the leading airport parking company BCP. In its negotiations with some airports, Ryanair asked for parking revenue sharing as a condition to serve the airports (Fu and Zhang, 2009).
} 
complementarity between the passenger flights and the concession consumption brought about by the flights, which may improve welfare. Essentially, passengers traveling through the airport also create a demand for concession consumption. As an airport depends on airlines to bring in passengers, sharing some of its concession revenues with the carriers will encourage them to expand output, which may in turn improve profit of the whole airport-airlines chain as well as social welfare. However, revenue sharing can cause a negative effect on airline competition as an airport may strategically share revenue with its dominant airlines, further strengthening these firms' market power. The US Federal Aviation Administration (FAA) has expressed concerns over airports' practice of offering particular airlines favorable terms, because such a special treatment of one particular airline may harm competition in the (downstream) airline markets (FAA, 1999). 2 Since 1995, the competition authority of the European Union, and later the European Commission, have ruled against several major airports in Belgium, Finland and Portugal concerning their practice of charging lower prices to home carriers (Barbot, 2006, 2009a).

For the last several years, the effects of vertical relationships between airports and airlines have received growing attention from researchers. In addition to Fu and Zhang (2009), Auerbach and Koch (2007) and Barbot (2009a, 2009b) found that cooperation between an airport and its airlines can bring benefits to the alliance members in terms of increased traffic volume and operation efficiency. In this paper we extend the previous work on airport-airline vertical cooperation, focusing on the effects of concession revenue sharing. More specifically, we consider that carriers may provide complementary, independent or substitutable services, and that the proportions of revenue sharing may be outside of the range of $[0,1]$. The latter allows us to compare alternative sharing arrangements. Further, unlike the previous studies, our analysis is conducted with general demand and cost functional forms.

We find that the degree of sharing will be affected by how carriers' services are related to each other. In particular, when carriers provide

\footnotetext{
2 Previous studies (e.g., FAA, 1999; GAO, 1997; Dresner et al., 2002; see also Hartmann, 2006, for a useful review on the topic) suggest that airline entry may be deterred if the dominant airline controls key airport facilities. Apparently, such a strategy by the dominant carrier would require at least implicit consent/cooperation from the airport. In the US, large and medium airports that meet a certain threshold of airline concentration are now required to submit competition plans as mandated by the 'Wendell H. Ford Aviation Investment and Reform Act for the $21^{\text {st }}$ Century’ legislated in 2000.
}

substitutable services, the sharing proportions might become negative if horizontal substitutability is sufficiently strong and the fixed (transfer) payments between the airport and carriers are feasible (referred to as the 'two-part revenue sharing'). The negative sharing allows the airport to penalize the over-competing airlines so as to support prices in the output market and improve profit. In these situations, while revenue sharing improves the total airport-airlines channel profit, it reduces social welfare. If the fixed payments are not feasible, under the resulting 'pure revenue sharing' the airport will, for the cases of independent or complementary services, share less concession revenue with its carriers than would be under the two-part revenue sharing. For the substitutes case however, the sharing-proportions comparison between the two types is in general ambiguous. In the special case of negative sharing, the pure revenue sharing results in not only a higher sharing proportion, but also a higher welfare level if carriers are sufficiently symmetric, than the two-part revenue sharing.

Our second objective in this paper is to investigate revenue sharing for multiple, competing airports. In general, very few papers in the airport literature have examined the case of competing airports analytically.3 This is understandable given the local monopoly nature of an airport. The situation is changing, however. The world has experienced a rapid growth in air transport demand since the 1970s, and many airports have been built or expanded as a result. This has led to a number of multi-airport regions such as greater London in the UK and several metropolitan areas in the US (e.g., San Francisco, Chicago, New York, Washington, Dallas, Detroit, Huston, and Los Angeles) within which airports may compete with each other. At the same time, the dramatic growth of low-cost carriers (e.g., Southwest Airlines in the US and Ryanair in Europe) has enabled some smaller and peripheral airports to cut into the catchment areas of large airports. Starkie (2008) conducted an overview of UK airports from the perspective of a business enterprise. He concluded that effective competition between airports is possible and a competitive airport industry can be financially viable. Taken together, these observations suggest that it is important to investigate the effects of revenue sharing in the

\footnotetext{
${ }^{3}$ For example, Fu and Zhang (2009) examined revenue sharing only for a monopoly airport. The few exceptions include Gillen and Morrison (2003), who examined two competing airports in the context of a full-service carrier and a low-cost carrier. More recently, Basso and Zhang (2007) provided a general examination of airport competition with congestion and non-atomistic airlines at each airport, and Barbot (2009a) examined airport-airline interactions (collusion, in particular) using a spatial model similar to that of Basso and Zhang. The issues of concession revenues and revenue sharing were not considered in these papers.
} 
context of multiple, competing airports.

We find that airport competition will result in a higher degree of revenue sharing than would be had in the case of single airports. Nevertheless, the airport-airline chains may derive lower profits through this revenue-sharing rivalry: in effect, the airports are trapped by the incentive structure of the environment, and the situation is similar to a classic Prisoners' Dilemma. As the airport-airline chains move further away from their joint profit maximum, social welfare rises beyond the level achievable by single airports. Our analysis also showed that airline market structure can have a bearing on revenue sharing arrangements at not only the airport in question, but also its competing airports.

The paper is organized as follows. Section 2 sets out the basic model and examines the revenue-sharing equilibrium for a single airport with multiple airlines. Section 3 examines revenue sharing for the general case of competing airports with each having an arbitrary number of carriers. Section 4 investigates the pure revenue sharing and compares its effects with those of the two-part revenue sharing. Section 5 contains concluding remarks.

\section{Single Airport with Multiple Airlines}

\subsection{Basic model}

Consider, in this section, that a single airport provides aeronautical service to airlines, for which it imposes a charge. ${ }^{4}$ In our modeling this charge is represented by a per-passenger fee $w(>0)$, and is regulated and cannot be changed unilaterally by either the airport or airlines. ${ }^{5}$ We have two carriers, labeled as $i=1,2$, operating from the airport, although the analysis and results extend immediately to the $n$-carrier case (see, e.g., Section 3.2). They face inverse demands $p^{i}\left(q_{1}, q_{2}\right)$, which satisfy the usual properties of $p_{i}^{i}<0$ and

$$
p_{1}^{1} p_{2}^{2}-p_{2}^{1} p_{1}^{2}>0
$$

with subscripts denoting partial derivatives. ${ }^{6}$ The

\footnotetext{
${ }^{4}$ For example, at the Hong Kong airport this charge consists of runway charge, aircraft parking fee, and terminal building charge, with each component accounting for $68.7 \%, 6.6 \%$ and $24.7 \%$, respectively (Zhang and Zhang, 2003).

${ }^{5}$ Since price discrimination (on aeronautical charges) by an airport is prohibited by the International Air Transport Association (IATA) rules, all airlines serving the airport face the same $w$.

${ }^{6}$ While $p_{i}^{i}<0$ indicates the usual property of

downward-sloping demands, $p_{1}^{1} p_{2}^{2}-p_{2}^{1} p_{1}^{2}>0$ refers to the property of 'own effects' dominating 'cross effects' in demand
}

airlines' revenue from providing aviation service is then given by $R^{i}\left(q_{1}, q_{2}\right)=p^{i}\left(q_{1}, q_{2}\right) q_{i}$.

The revenue functions can be used to define how one carrier's output is related to the other's. There are three possible cases: i) Complements: two airlines offer complementary services in the sense that

$$
\begin{aligned}
& R_{j}^{i}\left(q_{1}, q_{2}\right)=p_{j}^{i}\left(q_{1}, q_{2}\right) q_{i}>0 \\
& , R_{i j}^{i}\left(q_{1}, q_{2}\right)>0,
\end{aligned}
$$

i.e., increasing carrier $j$ 's output increases both the total and marginal revenues of carrier $i$ (here, and below, if the indices $i$ and $j$ appear in the same expression, then it is to be understood that $i \neq j.)^{7}$ In the present context, services provided by a trunk airline and a feeder airline - with their passengers connecting at the airport - may be considered as complements. Another example would be that two airlines engage in some form of strategic alliances or code-sharing arrangements (e.g., Brueckner, 2001; Brueckner and Whalen, 2000.). ii) Independent services:

$$
R_{j}^{i}\left(q_{1}, q_{2}\right)=p_{j}^{i}\left(q_{1}, q_{2}\right) q_{i}=0
$$

i.e., the airlines' services are unrelated in demand. (Note, in this case, that $R_{j}^{i}\left(q_{1}, q_{2}\right)=0$ implies

$$
\begin{aligned}
& R_{i j}^{i}\left(q_{1}, q_{2}\right)=0 \text {.) (iii) } \underline{\text { Substitutes: }} \\
& R_{j}^{i}\left(q_{1}, q_{2}\right)=p_{j}^{i}\left(q_{1}, q_{2}\right) q_{i}<0, \\
& R_{i j}^{i}\left(q_{1}, q_{2}\right)<0,
\end{aligned}
$$

i.e., increasing carrier $j$ 's output reduces both the total and marginal revenues of carrier $i$. For instance, two competing trunk carriers likely provide substitutes at an airport, so do two competing feeder carriers.

We consider that for each passenger going through the airport, a (net) concession revenue $h$ $(>0)$ is derived. ${ }^{8}$ How this revenue is shared

functions. As noted by Dixit (1986, p. 108), the dominance of own-effects over cross-effects is a standard assumption in models of oligopoly.

7 The first inequality in (1) shows (gross) complements between the airline services, whereas the second inequality implies 'strategic complements' (Bulow et al., 1985). That the former implies the latter holds for most (but not all) plausible demand structures; it certainly holds when demand functions are linear. In other words, the fact that services are complements is conducive to their strategic complementarity. Restricting attention to strategic complementarity is a standard practice in oligopoly models (Dixit, 1986; Tirole, 1988). Similar observations on 'substitutes' and 'strategic substitutes' hold for the substitutes case discussed next. We shall, as is common in the literature, refer to these two cases simply as 'complements' and 'substitutes.'

${ }^{8}$ This formulation of concession surplus has been used in, e.g. Zhang and Zhang (1997, 2003), Oum et al. (2004) and Fu and 
between the airport and airlines is modeled as a two-stage game. In the first stage, the airport offers carrier $i$ to share proportion $r_{i}$ of the revenue $h q_{i}$ in exchange for a fixed fee $f_{i}$, subject to the carrier's participation constraint. ${ }^{9}$ In this two-part sharing arrangement, no restriction is imposed on $r_{i}$; consequently, $r_{i}$ can be less than zero or greater than one. In the second stage, airlines interact with each other in Cournot fashion. ${ }^{10}$ The subgame perfect equilibrium of this two-stage game is referred to as the 'revenue sharing equilibrium.'

\subsection{Revenue-sharing equilibrium}

The revenue-sharing equilibrium is solved in the standard backward fashion.

Stage two: Given sharing option $\left(r_{i}, f_{i}\right)$, each carrier's profit is:

$$
\pi^{i}\left(q_{1}, q_{2}\right)=R^{i}\left(q_{1}, q_{2}\right)-C_{i}\left(q_{i}\right)-w q_{i}+r_{i} h q_{i}-f_{i},
$$

where $C_{i}\left(q_{i}\right)$ denotes carrier $i$ 's production cost. Thus for carrier $i$, the total operating cost net of fixed payment $f_{i}$ equals $C_{i}\left(q_{i}\right)+w q_{i}$. The Cournot-Nash equilibrium is characterized by the first-order conditions,

$\pi_{i}^{i}\left(q_{1}, q_{2}\right)=R_{i}^{i}\left(q_{1}, q_{2}\right)-C_{i}^{\prime}\left(q_{i}\right)-w+r_{i} h=0$, (5) and the second-order conditions $\pi_{i i}^{i}\left(q_{1}, q_{2}\right)=R_{i i}^{i}\left(q_{1}, q_{2}\right)-C_{i}^{\prime \prime}\left(q_{i}\right)<0$. Both the second-order conditions and the stability condition, $\quad J \equiv \pi_{11}^{1} \pi_{22}^{2}-\pi_{12}^{1} \pi_{21}^{2}>0 \quad$, are assumed to hold over the entire region of interest. ${ }^{11}$

Zhang (2009). It is, nevertheless, a simple representation where concession surplus is strictly complementary to passenger volume. For an alternative and perhaps more realistic formulation, see Czerny (2006).

9 Thus we investigate the effect of a 'two part' revenue-sharing scheme under which fixed payments are possible. Such a model can be used to examine the incentive for vertical airport-airline cooperation - i.e., taking account of the profit for an airport-airline channel as a whole - and may also be consistent with situations in which airports and airlines can commit to medium-/long-term cooperation. Nonetheless, such fixed payments between airports and airlines might not be feasible in certain situations, owing to the difficulty in their agreeing to the right amount of payments, or to the preference for simpler revenue-sharing arrangements that do not involve any medium-/long-term commitment. We will, in Section 4, examine a 'pure' sharing contract that restricts fixed payments $f_{i}$ to zero.

${ }^{10}$ Recent studies on airport pricing and capacity investment that have incorporated imperfect competition of air carriers at an airport (e.g., Brueckner, 2002; Pels and Verhoef, 2004; Zhang and Zhang, 2006; Basso, 2008) have assumed Cournot behavior. Brander and Zhang (1990, 1993), for example, find some empirical evidence that rivalry between duopoly airlines is consistent with Cournot behavior

11 This assumption implies that the Cournot equilibrium exists and is unique (e.g., Friedman, 1977). Note that if carriers face
The solution to (5) yields the second-stage equilibrium quantities, which are functions of the first-stage variables $\left(r_{1}, r_{2}\right)$. (Since fixed payments $f_{1}$ and $f_{2}$ enter the firms' profit functions (4) as constants, they won't affect the equilibrium quantities.) Denoting the equilibrium quantities as $q_{i}^{*}\left(r_{1}, r_{2}\right)$, substituting them into (5) and totally differentiating the resulting identity with respect to $r_{i}$, we obtain

$$
\begin{aligned}
& \partial q_{i}^{*} / \partial r_{i}=-h \pi_{j j}^{j} / J, \\
& \partial q_{j}^{*} / \partial r_{i}=h \pi_{j i}^{j} / J .
\end{aligned}
$$

It follows immediately that $\partial q_{i}^{*} / \partial r_{i}>0$, while $\partial q_{j}^{*} / \partial r_{i}$ having the same sign as $\pi_{j i}^{j}=R_{j i}^{j}$, which by (1), (2) and (3) leads to:

Lemma 1. (i) $\partial q_{i}^{*} / \partial r_{i}>0$; and (ii) $\partial q_{j}^{*} / \partial r_{i}>0,=0$, and $<0$ for carriers, producing complements, independent services, and substitutes, respectively.

Thus an increase in the share of concession revenue to carrier $i$ increases $i$ 's output. The reason is that an increase in $r_{i}$ will improve carrier i's marginal profitability, owing to the multi-output complementarity between passenger flights and concession consumption. Furthermore, an increase in $r_{i}$ increases, not affects, and decreases carrier $j$ 's output if the carriers offer complementary, independent, and substitutable services, respectively. For the case of substitutes, since that $\pi_{j i}^{j}=R_{j i}^{j}<0$ ensures a downward-sloping 'reaction function' for each carrier (defined by (5) in the output space), an increase in $r_{i}$ will, by increasing carrier $i$ 's marginal profit, shift its reaction function outward. This will move the equilibrium quantities downward along $j$ 's reaction function, thereby increasing $q_{i}^{*}$ and decreasing $q_{j}^{*}$. For complements, on the other hand, that $\pi_{j i}^{j}=R_{j i}^{j}>0$ ensures an upward-sloping reaction function for each firm. An increase in $r_{i}$ will again shift i's reaction function outward, moving the equilibrium quantities upward along $j$ 's reaction function, thereby increasing both $q_{i}^{*}$ and $q_{j}^{*}$. Finally, if the services are independent, then an increase in $r_{i}$ does not affect $q_{j}^{*}$, as expected.

linear demands, then all these conditions will be satisfied. 
Stage one: Revenue-sharing structures therefore influence subsequent airline quantities, which in turn will affect the airport's profit. Assume, for simplicity, that the airport's fixed cost is zero and its marginal cost is constant and normalized to zero. The airport's profit, denoted by $\Pi$, is then given by: ${ }^{12}$

$\Pi=w \cdot\left(q_{1}^{*}+q_{2}^{*}\right)+\left[\left(1-r_{1}\right) h q_{1}^{*}+\left(1-r_{2}\right) h q_{2}^{*}\right]+f_{1}+f_{2},(7)$ where the second-stage equilibrium outputs are taken into account. There are three components in $\Pi: \mathrm{i})$ the aeronautical revenue (profit) given by $w \cdot\left(q_{1}+q_{2}\right)$; (ii) the residual concession revenue given by the bracketed term in (7); and (iii) the fixed payment collected from carriers, $f_{1}+f_{2}$.

The airport chooses $\left(r_{1}, r_{2}\right)$ and $\left(f_{1}, f_{2}\right)$ to maximize $\Pi$. While $f_{i}$ won't, as indicated above, affect the second-stage equilibrium outputs, $\partial \Pi / \partial f_{i}=1$ by (7). Consequently, the airport should, given its Stackelberg leader's role, charge the airlines a fee as high as possible subject to their participation constraint $\pi^{i} \geq \pi_{0}^{i}$, with $\pi_{0}^{i}$ being carrier i's reservation profit, $i=1,2$. Assume, without loss of generality, that each carrier receives its reservation profit. (Hence, all the benefits from improvements in performance go to the airport.) This participation constraint implies, using (4), that

$$
\begin{gathered}
f_{i}=R^{i}\left(q_{1}^{*}, q_{2}^{*}\right)-C_{i}\left(q_{i}^{*}\right)-w q_{i}^{*}+r_{i} h q_{i}^{*}-\pi_{0}^{i}, \\
i=1,2,
\end{gathered}
$$

where equilibrium outputs $q_{i}^{*}$ are functions of $r_{1}$ and $r_{2}$. With (8), airport profit (7) becomes:

$\Pi\left(r_{1}, r_{2}\right)=\sum\left[R^{i}\left(q_{1}^{*}, q_{2}^{*}\right)-C_{1}\left(q_{i}^{*}\right)+h q^{*}-\pi_{0}^{i}\right] \equiv v\left(q_{1}^{*}\left(r_{1}, r_{2}\right), q_{2}^{*}\left(r_{1}, r_{2}\right)\right) \cdot$

Thus, the revenue-sharing equilibrium is characterized by the first-order conditions,

$$
\begin{gathered}
\partial \Pi / \partial r_{i}=v_{i} \cdot\left(\partial q_{i}^{*} / \partial r_{i}\right)+v_{j} \cdot\left(\partial q_{j}^{*} / \partial r_{i}\right)=0, \\
i=1,2,
\end{gathered}
$$

where

$v_{i}\left(\equiv \partial v / \partial q_{i}\right)=R_{i}^{i}\left(q_{1}^{*}, q_{2}^{*}\right)-C_{i}^{\prime}\left(q_{i}^{*}\right)+h+R_{i}^{j}\left(q_{1}^{*}, q_{2}^{*}\right)$

. By (5), $v_{i}$ can be rewritten as:

$v_{i}=w+\left(1-r_{i}\right) h+R_{i}^{j}\left(q_{1}^{*}, q_{2}^{*}\right)$.

Consider first the case where carriers' services are independent. It can be easily seen from (10), (11) and (2) that the equilibrium sharing proportions are given by (superscript $I$ for 'independent services'):

$$
r_{i}^{I}=1+(w / h), i=1,2,
$$

which are strictly positive. Revenue sharing therefore improves the airport's profit - here, the

\footnotetext{
12 Throughout the paper, we use capital letter $\Pi$ to denote airport profit, while lower case $\pi$ denoting airline profit.
}

profit gain is due to the internalization of a demand complementarity between the flights and concession consumption. Further, even if $r_{i}=1$, the profit will rise with $r_{i}$ going beyond the 'full' share. Basically, the two-part revenue sharing resolves the well-known 'double marginalization' problem in a vertical structure (e.g., Tirole, 1988).

The independent-services case turns out to be a useful benchmark for the cases of substitutes and complements. By first-order conditions (10) it follows:

$v_{1} \cdot\left(\partial q_{1}^{*} / \partial r_{1}\right)+v_{2} \cdot\left(\partial q_{2}^{*} / \partial r_{1}\right)=0$,
$v_{1} \cdot\left(\partial q_{1}^{*} / \partial r_{2}\right)+v_{2} \cdot\left(\partial q_{2}^{*} / \partial r_{2}\right)=0$,

which give rise to

$v_{2} \cdot\left[\left(\partial q_{1}^{*} / \partial r_{2}\right)\left(\partial q_{2}^{*} / \partial r_{1}\right)-\left(\partial q_{1}^{*} / \partial r_{1}\right)\left(\partial q_{2}^{*} / \partial r_{2}\right)\right]=0$ This equation, by (6), reduces further to $v_{2} h^{2}\left(\pi_{12}^{1} \pi_{21}^{2}-\pi_{11}^{1} \pi_{22}^{2}\right) / J=0 \Rightarrow-v_{2} h^{2}=0 \Rightarrow v_{2}=0$. Plugging $v_{2}=0$ into (13.1) we immediately have $v_{1}=0$. It follows from (11) that

$$
r_{i}=[1+(w / h)]+\left(R_{i}^{j} / h\right), i=1,2
$$

If airline services are complements, then $R_{i}^{j}>0$; consequently (superscript $C$ for 'complements'),

$$
r_{i}^{C}>1+(w / h)=r_{i}^{I}, \quad i=1,2 .
$$

If airline services are substitutes, then $R_{i}^{j}<0$ and so equation (14) yields (superscript $S$ for 'substitutes')

$$
r_{i}^{S}<1+(w / h)=r_{i}^{I}, \quad i=1,2 .
$$

The above discussion leads therefore to:

Proposition 1. At the revenue-sharing equilibrium with a single airport, the sharing proportions are $r_{i}^{I}=1+(w / h)$ when carriers' services are independent, $i=1,2$. The sharing proportions are greater (smaller, respectively) than $r_{i}^{I}$ when carriers produce complements (substitutes, respectively).

The explanation for the deviations from the independent-services benchmark is straightforward. When services are complementary, the carriers are unable to internalize such complementarity by themselves. However, the airport, as a first mover, can achieve this by manipulating revenue-sharing proportions - here, by increasing the sharing proportions beyond $r_{i}^{I}$. In the substitutes case, on the other hand, horizontal (output) substitutability 
will lead to a failure of coordination between competing airlines, resulting in their producing too much with respect to what would be best for them as a whole. Anticipating this, the airport uses revenue sharing as a device to coordinate airline competition downstream. In particular, a smaller sharing proportion than the independent-services benchmark will, by Lemma 1 , reduce industry output, thus lessening excessive production by carriers.

It is important to point out that for the substitutes case, the sharing proportions might become negative. This is because horizontal substitutability works in an opposite direction of the flights-concessions demand complementarity discussed above, in terms of the amount of production the airport would like to induce. The optimal level of revenue sharing, $r_{i}^{S}$, is set to balance these two effects. Thus, $r_{i}^{s}$ depends on the degree of substitutability between carriers' services. Numerical examples are constructed at the end of this section, in which horizontal substitutability is so strong that $r_{i}^{S}$ become negative.

\subsection{Comparison with the no-sharing regime}

Our concern now is to compare the revenue-sharing equilibrium with the situation where airport-airline revenue sharing is not allowed, characterized by $r_{i}=f_{i}=0$. First, for the cases of complements and independent services, it is clear from Lemma 1 and Proposition 1 that revenue sharing will increase output and improve profit. Define social welfare as the sum of the airport-airline profit and consumer (passenger) surplus:

$W\left(r_{1}, r_{2}\right)=U\left(q_{1}^{*}, q_{2}^{*}\right)-C_{1}\left(q_{1}^{*}\right)-C_{2}\left(q_{2}^{*}\right)+h_{q}^{*}+h \stackrel{*}{q}=\phi\left(q_{1}^{*}, q_{2}^{*}\right),(17)$

where $U\left(q_{1}, q_{2}\right)$ is the consumer utility function in the usual industry (partial equilibrium) analysis, with $\partial U / \partial q_{i}=p^{i}$. Although passengers may derive surplus also from their concession consumption, such surplus per passenger is assumed constant and further normalized to zero, thus giving rise to formulation (17). Differentiating $W$ with respect to $r_{i}$ yields:

$$
\left.\partial W / \partial_{i}=\left(p^{i}-C_{i}+h\right)\left(\partial q_{i}^{*} / \partial_{i}\right)+\left(p^{j}-C_{j}+h\right) \partial q_{j}^{*} / \partial_{i}\right) \cdot(18)
$$

Since $p^{i}-C_{i}^{\prime}>0$ (positive markups in oligopoly), the output expansion identified above leads immediately to $\partial W / \partial r_{i}>0$ and thus, revenue sharing improves welfare.

As for prices, it can be easily seen (from below) that they will fall if carriers' services are independent. For the complements case, the effect is not as straightforward. Differentiating $p^{i}\left(q_{1}^{*}, q_{2}^{*}\right)$ with respect to $r_{i}$ and $r_{j}$ yields

$$
\begin{aligned}
& \partial p^{i} / \partial r_{i}=p_{i}^{i} \cdot\left(\partial q_{i}^{*} / \partial r_{i}\right)+p_{j}^{i} \cdot\left(\partial q_{j}^{*} / \partial r_{i}\right),(19) \\
& \partial p^{i} / \partial r_{j}=p_{i}^{i} \cdot\left(\partial q_{i}^{*} / \partial r_{j}\right)+p_{j}^{i} \cdot\left(\partial q_{j}^{*} / \partial r_{j}\right),
\end{aligned}
$$

respectively. With carriers' services being complementary, the first term on the right-hand side (RHS) of (19.1) is negative (recall $p_{i}^{i}<0$ and Lemma 1) whilst the second term is positive. Similarly, the first term on the RHS of (19.2) is negative whilst the second term is positive. Under 'symmetry' however, the overall effects will be negative for both (19.1) and (19.2), as is shown below (Proposition 2). By 'symmetry' we mean (i) carriers have identical cost functions and face symmetric demands, and (ii) at the equilibrium, carriers have the same sharing contract (i.e., $r_{1}=r_{2}$ and $f_{1}=f_{2}$ ). The symmetry condition will also be used in the comparison for the substitutes case (see Proposition 2).

Proposition 2. At the revenue-sharing equilibrium with a single airport,

1. when carriers provide independent or complementary services, (i) outputs and social welfare are greater and (ii) under symmetry, prices are lower, than in the absence of revenue sharing;

2. when carriers provide substitutable services and are symmetric, (i) outputs and social welfare are greater (smaller, respectively) and (ii) prices are lower (higher, respectively), than in the absence of revenue sharing if $r_{i}^{S}>0 \quad\left(r_{i}^{S}<0\right.$, respectively).

Proof: 1 . We only need to show the price effect for complementary services (the other parts have been shown in the text). Use $\Delta$ to denote any difference of variables between the revenue-sharing regime and no-sharing regime. Applying the mean value theorem (MVT) to the function $p^{i}\left(q_{1}^{*}, q_{2}^{*}\right)$ yields:

$$
\Delta p^{i}=p_{i}^{i} \cdot \Delta q_{i}^{*}+p_{j}^{i} \cdot \Delta q_{j}^{*},
$$

where $p_{i}^{i}$ and $p_{j}^{i}$ are evaluated at some point

between $\left(q_{1}^{O}, q_{2}^{O}\right)$ and $\left(q_{1}^{C}, q_{2}^{C}\right)$, with superscript $O$ denoting variables associated with the no-sharing regime. Under symmetry,

$\Delta q_{i}^{*}=\Delta q_{j}^{*}>0$ from part (i). Consequently, $\Delta p^{i}=\left(p_{i}^{i}+p_{j}^{i}\right) \Delta q_{i}^{*}<0$ with the inequality following from the condition $p_{1}^{1} p_{2}^{2}-p_{2}^{1} p_{1}^{2}>0$ and symmetry: noting that symmetry implies 


$$
\left(p_{i}^{i}+p_{j}^{i}\right)\left(p_{i}^{i}+p_{j}^{i}\right)>0
$$

and hence

$$
p_{i}^{i}+p_{j}^{i}<0 .
$$

2. (i) Applying MVT to $q_{i}^{*}\left(r_{1}, r_{2}\right)$ yields $\Delta q_{i}^{*}=\left(\partial q_{i}^{*} / \partial r_{i}\right) \Delta r_{i}+\left(\partial q_{i}^{*} / \partial r_{j}\right) \Delta r_{j}$, with $\partial q_{i}^{*} / \partial r_{i}$ and $\partial q_{i}^{*} / \partial r_{j}$ evaluated at some point between $\left(r_{1}^{O}, r_{2}^{O}\right)$ and $\left(r_{1}^{S}, r_{2}^{S}\right)$. Under symmetry, $\Delta r_{i}=\Delta r_{j}$ and $\partial q_{i}^{*} / \partial r_{j}=\partial q_{j}^{*} / \partial r_{i}$; consequently,

$\Delta q_{i}^{*}=\left[\partial\left(q_{i}^{*}+q_{j}^{*}\right) / \partial r_{i}\right] \Delta r_{i}=h \cdot\left(\pi_{j i}^{j}-\pi_{j j}^{j}\right) \Delta r_{i}$

Since $\pi_{j i}^{j}-\pi_{j j}^{j}>0$ under symmetry and the stability and second-order conditions, $\Delta q_{i}^{*}$ must have the same sign as $\Delta r_{i} \equiv r_{i}^{S}-r_{i}^{O}=r_{i}^{S}$ (recall $r_{i}^{O}=0$ ).

For the welfare comparison, applying MVT to $\varphi\left(q_{1}^{*}, q_{2}^{*}\right)$ in (17) yields $\Delta \varphi=\varphi_{i} \Delta q_{i}^{*}+\varphi_{j} \Delta q_{j}^{*}$, where $\varphi_{i}$ and $\varphi_{j}$ are evaluated at some point between $\left(q_{1}^{O}, q_{2}^{O}\right)$ and $\left(q_{1}^{S}, q_{2}^{S}\right)$. Under symmetry, $\Delta q_{i}^{*}=\Delta q_{j}^{*} \quad$. Consequently, $\Delta \varphi=\left(\varphi_{i}+\varphi_{j}\right) \Delta q_{i}^{*}$ has the same sign as $\Delta q_{i}^{*}$, because $\varphi_{i}=p^{i}-C_{i}^{\prime}+h>0$. The welfare result then follows from the above quantity comparison.

(ii) Applying MVT to $p^{i}\left(q_{1}^{*}, q_{2}^{*}\right)$ yields $\Delta p^{i}=p_{i}^{i} \Delta q_{i}^{*}+p_{j}^{i} \Delta q_{j}^{*}$, where $p_{i}^{i}$ and $p_{j}^{i}$ are evaluated at some point between $\left(q_{1}^{O}, q_{2}^{O}\right)$ and $\left(q_{1}^{S}, q_{2}^{S}\right)$. With $\Delta q_{i}^{*}=\Delta q_{j}^{*}$ under symmetry, $\Delta p^{i}=\left(p_{i}^{i}+p_{j}^{i}\right) \Delta q_{i}^{*}$ has the opposite sign as $\Delta q_{i}^{*}$, because $p_{i}^{i}<0$ and, by (3), $p_{j}^{i}<0$. The result then follows from the above quantity comparison.Q.E.D.

Although some of the comparisons in Proposition 2 are carried out under 'perfect' symmetry between the firms, a closer look at the above proof indicates that small asymmetries won't undermine the results. Proposition 2 shows that when carriers offer complementary and unrelated services, revenue sharing between an airport and its airlines improves welfare. The welfare improvement arises because prices exceed marginal costs in the oligopolistic airline market and revenue sharing reduces prices (or equivalently, expands outputs).

When carriers provide substitutable services, revenue sharing may or may not improve welfare, depending on the sign of equilibrium sharing proportions $r_{i}^{S}$. As indicated above, the sign of $r_{i}^{S}$ will in turn depend on the degree of substitutability between carriers' services. To capture such an impact, we need to impose more structures on the model. ${ }^{13}$ Specifically, a linear (inverse) demand is specified: $p^{i}=1-b q_{i}-k q_{j} \quad$, with $\quad b>0 \quad$ and $k \in(-b, b)$, which ensure downward-sloping demands and the own price effects dominating the cross price effects. It is clear that carriers' services are complements, independent and substitutes when $k<0,=0$ and $>0$, respectively. Carriers' marginal costs $C_{1}$ and $C_{2}$ are constant and $c_{1}=c_{2}$. In the simulation, parameters are chosen to ensure positive outputs and marginal revenues.

Figure 1 reports the effects of airline service substitutability, where we define $k=m \cdot b$ with $m \in(-0.1,1)$. Thus, negative $m$ indicates horizontal complementarity, whilst for positive $m$, larger $m$ 's mean increasingly substitutable services. As expected, the airport shares a high percentage of concession revenue $-r_{1}\left(=r_{2}\right)$ greater than 1 with airlines when the latter produce complements $(m<0)$ so as to internalize horizontal complementarity. The (equilibrium) sharing proportions, $r_{i}^{S}$, fall when airline services become increasingly substitutable. When horizontal substitutability becomes sufficiently strong, $r_{i}^{S}$ turns into a negative value. Such a 'negative revenue sharing' allows the airport to penalize the over-competing airlines so as to support prices in the output market and improve profit for the whole airport-airlines channel. While carriers pay a higher price (than airport charge $w$ ) per unit of output, they are nevertheless compensated for with fixed payments from the airport - noticing in the figure that the fixed fee becoming negative. ${ }^{14}$ In such a

\footnotetext{
${ }^{13}$ Examining how equilibrium results change with substitutability (i.e., when airline services become more substitutable to each other) is also important, since there are situations in which airports or policy makers can 'moderate' such substitutability. For example, only a few Asian cities are served by multiple airports and as a result, low-cost carriers (LCC) are often forced to use the same airport as competing full-service carriers (FSC). Recently, airports in, e.g., Kuala Lumpur and Singapore chose to build separate LCC terminals which offer lower quality of airport service with less charge (Zhang et al., 2009). Such a measure would make LCCs' services less substitutable to the services provided by FSCs.

14 The negative revenue sharing arrangement or its variants are also observed in practice. There are cases, for instance, where airports may make one-shot investments (for carriers) to offset
} 
case, the output and welfare (not shown in Figure 1) with revenue sharing (the solid line in the figure) are less than those in the no-sharing case (the dotted line), as predicted by Proposition 2. Here, while revenue sharing improves the total channel profit (see the figure), it might reduce social welfare.

- The horizontal axis corresponds to substitutability parameter $m$, with $k=m \cdot b$, $m \in(-0.1,1)$

- - - Solid Line: Results with share revenue

- $\quad \cdots$ Dotted Line: Results without revenue sharing.

\section{Competing Airports \\ 3.1 Strategic revenue sharing}

We now consider two airports, represented by $i=1,2$, beginning with a situation of one carrier at each airport. (The case of multiple airlines will be considered in Section 3.2.) To save notation we continue to use $p^{i}\left(q_{1}, q_{2}\right)$ for the inverse demands faced by carriers, with $i$ denoting the $i^{\text {th }}$ airport's carrier (and $q_{i}$ its output). The two airports compete with each other in the sense that their airlines' services are substitutes in the eyes of passengers. More specifically, airline revenue functions $R^{i}\left(q_{1}, q_{2}\right) \quad\left(=p^{i}\left(q_{1}, q_{2}\right) q_{i}\right)$ satisfy the substitutes condition (3).

Airport-airline behavior is modeled again as a two-stage game: In the first stage, each airport offers its carrier to share proportion $r_{i}$ of concession revenue $h q_{i}$ in exchange for fixed fee $f_{i}$, subject to the carrier's participation constraint. In the second stage, airlines compete in Cournot fashion with their profits given by (4). Given this set-up, the second-stage equilibrium is characterized by (5), the same condition as in the single-airport case. Further, the equilibrium quantities - denoted again as $q_{i}^{*}\left(r_{1}, r_{2}\right)$ - have the comparative-static properties of Lemma 1: i.e., an increase in the sharing proportion by airport $i$ will increase its carrier's output while reducing output of the competing airport's carrier.

high airport charges. For example, Federal Express (FedEx) had been planning to move its Asia Pacific operating center from Subic Bay in the Philippines to Guangzhou in China since 2003. However, FedEx was concerned about the high operating costs in Guangzhou airport due to its high charges for fuel, airport and ATC (air traffic control) services which are regulated by the central government. To offset these high service charges and attract FedEx, the airport agreed to invest US\$300 million on infrastructures including exclusive aircraft parking space and taxi runways for the usage of FedEx. FedEx opened its Asia Pacific operating center in Guangzhou in February 2009. It now has 136 flights per week at the airport.
Taking the second-stage equilibrium outputs into account, each airport's profit in stage 1 are expressed,

$\Pi^{i}=w q_{i}^{*}+\left(1-r_{i}\right) h q_{i}^{*}+f_{i}, \quad i=1,2$.

The subgame perfect equilibrium then arises when each airport chooses its sharing contract $\left(r_{i}, f_{i}\right)$ to maximize $\Pi^{i}$, taking its rival's sharing contract at the equilibrium values. This revenue-sharing equilibrium with airport competition will be referred to as the 'rivalry (revenue sharing) equilibrium.' Without loss of generality the carriers are again assumed to receive their reservation profits $\pi_{0}^{i}$, $i=1,2$; consequently, each airport's profit can be rewritten as:

$\Pi^{i}\left(r_{1}, r_{2}\right)=R^{i}\left(q_{1}^{*}, q_{2}^{*}\right)-C_{i}\left(q_{i}^{*}\right)+h q^{*}-\pi_{0}^{i} \equiv v^{i}\left(q_{1}^{*}\left(r_{1}, r_{2}\right), q_{2}^{*}\left(r_{1}, r_{2}\right)\right) \cdot(21)$

The rivalry equilibrium is characterized by the first-order conditions,

$$
\begin{gathered}
\Pi_{i}^{i}=v_{i}^{i} \cdot\left(\partial q_{i}^{*} / \partial r_{i}\right)+v_{j}^{i} \cdot\left(\partial q_{j}^{*} / \partial r_{i}\right)=0, \\
i=1,2,
\end{gathered}
$$

where subscripts again denote partial derivatives

$$
\text { (e.g., } \Pi_{i}^{i} \equiv \partial \Pi^{i} / \partial r_{i}, \quad v_{i}^{i} \equiv \partial v^{i} / \partial q_{i}
$$

and

$$
\left.v_{j}^{i} \equiv \partial v^{i} / \partial q_{j}\right) \text {. }
$$

From (21), $\quad v_{i}^{i}=R_{i}^{i}\left(q_{1}^{*}, q_{2}^{*}\right)-C_{i}^{\prime}\left(q_{i}^{*}\right)+h$ which can by (5) be rewritten as:

$v_{i}^{i}=w+\left(1-r_{i}\right) h$.

For the rivalry equilibrium, since $v_{j}^{i}=R_{j}^{i}<0$, $\partial q_{i}^{*} / \partial r_{i}>0$ and $\partial q_{j}^{*} / \partial r_{i}<0$, it follows by (22) that $v_{i}^{i}<0$. Thus by (23), the equilibrium sharing proportions satisfy (superscript $R$ for 'rivalry equilibrium'),

$$
r_{i}^{R}>1+(w / h), \quad i=1,2 .
$$

It is interesting to compare this rivalry equilibrium with the 'non-rivalry (revenue sharing) solution,' which is obtained when the two airports were perceived as independent in the sense that $p_{j}^{i}\left(q_{1}, q_{2}\right)=0$. It can be easily seen from (22)-(23) that the non-rivalry sharing proportions are given by (superscript $N$ for 'non-rivalry solution'):

$$
r_{i}^{N}=1+(w / h), \quad i=1,2 .
$$

Comparing (25) with (24) leads to:

Proposition 3. The revenue-sharing proportions are greater at the rivalry revenue-sharing equilibrium than under the non-rivalry revenue-sharing solution, i.e., $r_{i}^{R}>r_{i}^{N}$ for $i=1,2$.

The non-rivalry regime is, from (25) and (12), 
similar to the case of a single (monopoly) airport examined in Section 2, as expected: Like a monopoly airport, each airport in the non-rivalry regime shares positive proportion $r_{i}^{N}=1+(w / h)$ of concession revenue with its carrier. While $r_{i}^{N}$ internalizes the flights-concessions demand complementarity, the rivalry revenue sharing involves an additional term $\delta_{i}$ - i.e., $r_{i}^{R}=r_{i}^{N}+\delta_{i}$ - which is unique to the case of competing airports. Since this additional effect works by indirectly influencing the behavior of the rival airport-airline pair - which in turn will improve profit of the airport-airline pair in question - the rivalry revenue sharing may be referred to as the 'strategic revenue sharing.' Proposition 3 therefore shows that airport competition will, owing to this strategic effect, result in a higher degree of revenue sharing than would be had in the case of single airports.

Next, the rivalry equilibrium is compared to the non-rivalry solution in terms of output, price, profit and social welfare. Here, welfare is the sum of passenger surplus and profits of the two airport-airline pairs; hence, it takes the same form as (17). The comparison results are stated as follows:

Proposition 4. Under symmetry, at the rivalry revenue-sharing equilibrium, (i) outputs are greater, (ii) prices are lower, (iii) airport profits are lower, and (iv) social welfare is higher, than at the non-rivalry revenue-sharing solution.

Proof: Use $\Delta$ to denote any difference of variables between the rivalry equilibrium and the non-rivalry solution. Here, we just show parts (i) and (iii); the proofs for parts (ii) and (iv) are similar to those of Proposition 2.

(i) Applying the mean value theorem (MVT) to $q_{i}^{*}\left(r_{1}, r_{2}\right)$

yields $\Delta q_{i}^{*}=\left(\partial q_{i}^{*} / \partial r_{i}\right) \Delta r_{i}+\left(\partial q_{i}^{*} / \partial r_{j}\right) \Delta r_{j}$, with $\partial q_{i}^{*} / \partial r_{i}$ and $\partial q_{i}^{*} / \partial r_{j}$ evaluated at some point between $\left(r_{1}^{N}, r_{2}^{N}\right)$ and $\left(r_{1}^{R}, r_{2}^{R}\right)$. Under symmetry, $\Delta r_{i}=\Delta r_{j}$ and $\partial q_{i}^{*} / \partial r_{j}=\partial q_{j}^{*} / \partial r_{i}$; consequently,

$\Delta q_{i}^{*}=\left[\partial\left(q_{i}^{*}+q_{j}^{*}\right) / \partial r_{i}\right] \Delta r_{i}=h \cdot\left(\pi_{j i}^{j}-\pi_{j j}^{j}\right) \Delta r_{i}$

Since $\pi_{j i}^{j}-\pi_{j j}^{j}>0$ under symmetry and the stability and second-order conditions, $\Delta q_{i}^{*} \equiv q_{i}^{R}-q_{i}^{N}$ must have the same sign as $\Delta r_{i} \equiv r_{i}^{R}-r_{i}^{N}$. By Proposition $3, r_{i}^{R}>r_{i}^{N}$ and hence $q_{i}^{R}>q_{i}^{N}$. (iii) Applying MVT to $\Pi^{i}\left(r_{1}, r_{2}\right)$, given by (21), yields $\Delta \Pi^{i}=\bar{\Pi}_{i}^{i} \Delta r_{i}+\bar{\Pi}_{j}^{i} \Delta r_{j}$, where $\bar{\Pi}_{i}^{i}$ and $\bar{\Pi}_{j}^{i}$ are evaluated at $\left(\bar{r}_{1}, \bar{r}_{2}\right)$ with $r_{i}^{N}<\bar{r}_{i}<r_{i}^{R} \quad$ (using Proposition 3). Since $\Delta r_{i}=\Delta r_{j}$ under symmetry and

$$
\Delta r_{i} \equiv r_{i}^{R}-r_{i}^{N}>0
$$

it follows that

$$
\Delta \Pi^{i}=\left(\bar{\Pi}_{i}^{i}+\bar{\Pi}_{j}^{i}\right)\left(r_{i}^{R}-r_{i}^{N}\right)
$$

and hence $\Delta \Pi^{i}<0$ if (and only if) $\bar{\Pi}_{i}^{i}+\bar{\Pi}_{j}^{i}<0$. By (21) and symmetry, it follows that

$$
\bar{\Pi}_{i}^{i}+\bar{\Pi}_{j}^{i}=\left(\bar{v}_{i}^{i}+\bar{v}_{j}^{i}\right)\left[\partial\left(q_{1}^{*}+q_{2}^{*}\right) / \partial r_{i}\right],
$$

where $\bar{v}_{i}^{i}$ and $\bar{v}_{j}^{i}$ are evaluated at $\bar{q}_{i}=q_{i}^{*}\left(\bar{r}_{1}, \bar{r}_{2}\right)$. By (23), $\bar{v}_{i}^{i}=w+\left(1-\bar{r}_{i}\right) h$ which is negative given that $\bar{r}_{i}>r_{i}^{N}=1+(w / h)$. Furthermore, since $\bar{v}_{j}^{i}=\bar{R}_{j}^{i}<0 \quad$ (substitutable airports) and

$$
\partial\left(q_{i}^{*}+q_{j}^{*}\right) / \partial r_{i}=h \cdot\left(\pi_{j i}^{j}-\pi_{j j}^{j}\right)>0,
$$

it follows that $\bar{\Pi}_{i}^{i}+\bar{\Pi}_{j}^{i}<0$.

Therefore, $\Delta \Pi^{i} \equiv \Pi^{i R}-\Pi^{i N}<0$. Q.E.D.

Proposition 4 shows that both airport-airline pairs will derive lower profits through this revenue-sharing rivalry: the rivalry results in their producing too much, thereby depressing the prices and profits. In effect, the pairs are trapped by the incentive structure of the environment. If one airport-airline pair ignores the possibility of strategic use of revenue-sharing contracts while the other pair shares revenue strategically, the first pair loses while the second pair gains relative to the non-strategic sharing arrangement. Here the situation is similar to a classic Prisoners' Dilemma. As the airport-airline pairs move further away from their joint profit maximum through such a revenue-sharing rivalry, social welfare nevertheless rises beyond the level achievable by single airports.

\subsection{Multiple airlines}

Section 3.1 studies the case of one carrier per airport. We now extend the analysis to a situation where there may be multiple competing airlines at each airport. Our second objective in this section is to show that the general demand structure used in Section 3.1 can be generated through explicit considerations of passenger behavior.

More specifically, our demand derivation follows Basso and Zhang (2007) by considering an 
infinite linear city, where potential consumers are distributed uniformly with a density of one consumer per unit of length. Two competing airports are located at 0 (airport 1 ) and 1 (airport 2) and there are $n_{i}$ carriers at airport $i, i=1,2$ (see Figure 2). At each airport, carriers produce homogeneous output, with total output $Q_{i}=\sum_{k=1}^{n_{i}} q_{i k}$ and market price $p^{i}$.

\section{catchment areas}

(adapted from Basso and Zhang, 2007)

The 'full price' faced by a consumer located at $0 \leq z \leq 1$ and who goes to airport 1 is given by $p^{1}+(4 t) \cdot z$, where $4 t \quad(>0)$ represents the consumer's transportation cost from $Z$ to location 0 . By choosing airport 1 or airport 2 (but not both) the consumer derives the following respective net utilities:

$$
\begin{array}{r}
U_{1}=V-p^{1}-(4 t) \cdot z, \\
U_{2}=V-p^{2}-(4 t) \cdot(1-z),
\end{array}
$$

where $V$ denotes (gross) benefit from air travel. ${ }^{15}$ Assuming everyone in the $[0,1]$ interval consumes, then the indifferent passenger $\tilde{Z} \in(0,1)$ is determined by setting $U_{1}=U_{2}$, or

$$
\tilde{z}=\frac{1}{2}+\frac{p^{2}-p^{1}}{8 t} .
$$

Given that airport 1 also captures consumers at its immediate left side, define $Z^{l}$ as the last passenger on the left side of the city who goes to airport 1 .

Similarly, define $z^{r}$ as the last passenger on the right side of the city who goes to airport 2 . With the uniformity and unit density of consumers, $z^{l}$ and $\mathrm{Z}^{r}$ are computed as:

$z^{l}=-\frac{V-p^{1}}{4 t}, \quad z^{r}=1+\frac{V-p^{2}}{4 t}$.

The airports' catchment areas are shown in Figure 2, and their demands are computed as:

\footnotetext{
${ }^{15}$ This is an 'address model' with positive linear transportation costs, and the differentiation of the two airports is captured by consumer transportation cost. Within a multi-airport region, for example, passengers may not necessarily choose an airport with cheaper airfare, but may go to a nearer airport - see the empirical studies by, e.g., Pels et al. (2001), Fournier et al. (2007) and Ishii et al. (2009). In addition to distance, other aspects of airport differentiation may be captured by extending the present formulation. For instance, Pels et al. (2000, 2001, 2003) have shown, using a hypothetical example and later the San Francisco Bay Area case study, that ground accessibility of an airport is the most important factor in affecting airport choices in a multi-airport market. Such differential ground access costs could be addressed by introducing a new parameter to the net-benefit functions (26).
}

$$
\begin{aligned}
& Q_{1}=\tilde{z}+\left|z^{l}\right|=\frac{1}{2}+\frac{p^{2}-p^{1}}{8 t}+\frac{V-p^{1}}{4 t}, \\
& Q_{2}=(1-\tilde{z})+\left(z^{r}-1\right)=\frac{1}{2}-\frac{p^{2}-p^{1}}{8 t}+\frac{V-p^{2}}{4 t} .
\end{aligned}
$$

From (29) the inverse demands are given by

$$
\begin{aligned}
& p^{i}\left(Q_{1}, Q_{2}\right)=(2 t+V)-3 t Q_{i}-t Q_{j}, \\
& \quad i, j=1,2 .
\end{aligned}
$$

which take the linear functional forms. This demand system has the properties of

$$
p_{i}^{i}=-3 t<0, \quad p_{1}^{1} p_{2}^{2}-p_{2}^{1} p_{1}^{2}=8 t^{2}>0,
$$

and substitutes condition (3).

To solve the two-stage airport competition game, we begin with an analysis of the second stage when airlines engage in intra- and inter-airport competition. Suppose for simplicity that carriers have linear costs $C(q)=F+c q$. Consider first that the two airports have the same number of carriers, i.e., $n_{1}=n_{2} \equiv n$. Then airline profits can be written as:

$$
\pi^{j k}\left(Q, Q_{2}, q_{k}\right)=p^{j}\left(Q, Q_{2}\right) \cdot q_{i k}-F-c q_{k k}-w q_{k}+r_{i} h q_{k}-f_{i} \text {. }
$$

The Cournot-Nash equilibrium is characterized by first-order conditions,

$$
\begin{gathered}
\frac{\partial \pi^{i k}\left(Q_{1}, Q_{2}, q_{i k}\right)}{\partial q_{i k}}=p^{i}-3 t q_{i k}-c-w+r_{i} h=0, \\
k=1, \ldots, n, \quad i=1,2,
\end{gathered}
$$

(and the corresponding second-order conditions, which hold as $\left.\partial^{2} \pi^{i k} / \partial q_{i k}^{2}=-6 t<0\right)$. Given the underlying symmetry of this set-up, the equilibrium quantities are easily obtained:

$$
\begin{gathered}
q_{i k}^{*}\left(r_{1}, r_{2}\right)=\frac{\left[3(n+1) r_{i}-n r_{j}\right] h}{(2 n+3)(4 n+3) t}+\frac{2 t+V-c-w}{(4 n+3) t}, \\
k=1, \ldots, n, \quad i=1,2 .
\end{gathered}
$$

Back to the first stage of the game, each airport's profit is:

$$
\begin{aligned}
& \Pi^{i}=w Q_{i}^{*}+\left(1-r_{i}\right) h Q_{i}^{*}+n f_{i}, \\
& i=1,2 .
\end{aligned}
$$

With the airline participation constraints, these profits can be rewritten as,

$\Pi^{i}\left(r_{1}, r_{2}\right)=\left[p^{i}\left(Q_{1}^{*}, Q_{2}^{*}\right)-c+h\right] Q_{1}^{*}-n \cdot\left(F+\pi_{0}^{i}\right)$.

Hence the rivalry equilibrium is characterized by first-order conditions,

$$
\begin{aligned}
& \prod_{i}=\left[w+\left(1-r_{i}\right) h-3\left(Q_{Q}^{*}-q_{k}^{*}\right)\right] \cdot\left(\partial Q^{*} / \partial_{i}\right)-t Q^{*} \cdot\left(\partial Q_{i}^{*} / \partial_{i}\right)=0 \text {, } \\
& i=1,2 \text {. }
\end{aligned}
$$

From (36) the equilibrium sharing proportions are obtained as, 


$$
r_{i}^{R}=1+\frac{w}{h}-\frac{\left(8 n^{2}-9\right)(2 t+V+h-c)}{n(20 n+21) h},
$$$$
i=1,2 \text {. }
$$

Notice from (37) that if $n=1$ (each airport has one carrier) then $r_{i}^{R}>1+(w / h)=r_{i}^{N}$, a result obtained in Section 3.1 (see Proposition 3). ${ }^{16}$ Further, it follows from (37) that $d r_{i}^{R} / d n<0, i=1,2$ : i.e., the sharing proportions decrease in the number of carriers serving the airports.

For the general case where airports 1 and 2 have $n_{1}$ and $n_{2}$ carriers respectively, the inverse demands are given by (30), where $Q_{i}=\sum_{k=1}^{n_{i}} q_{i k}$ is the aggregate demand at airport $i$. Solving the two-stage game yields:

$$
\begin{aligned}
& r_{i}^{R}=1+\frac{w}{h} \frac{\left[\left(8 n_{j}+9\right) n_{i}-9 n_{j}-9\right]\left(1 m_{i}+15(2 t+V+h-c)\right.}{n_{i}\left(28 a_{i} n_{j}+29 n_{i}+29 \eta_{j}+31 \not g h\right.}, \\
& \ldots i=1,2 .
\end{aligned}
$$

Note that when $n_{1}=n_{2}=n$, the above expression reduces to expression (37). From (38) it is straightforward to show that $d r_{i}^{R} / d n_{i}<0$ and $d r_{i}^{R} / d n_{j}>0$, leading to:

Proposition 5. At the rivalry equilibrium with $n_{1}$ and $n_{2}$ carriers at airports 1 and 2 respectively, $d r_{i}^{R} / d n_{i}<0$ and $d r_{i}^{R} / d n_{j}>0$ : i.e., the revenue-sharing proportion of an airport-airlines chain decreases in the number of carriers at its airport, and increases in the number of carriers at the competing airport. If $n_{1}=n_{2}=n$, then $d r_{i}^{R} / d n<0$.

The intuition behind $d r_{i}^{R} / d n_{i}<0$ is similar to that of Proposition 1 (the substitutes case): As $n_{i}$ rises (while holding $n_{j}$ constant) and airline competition intensifies, the total industrial output becomes increasingly excessive for the $i^{\text {th }}$ airport-airlines chain. Anticipating this airport $i$, as a first mover, has a greater incentive to discourage such excessive production, which can be achieved by a smaller sharing proportion. ${ }^{17}$ While this result is

\footnotetext{
${ }^{16}$ This result can also be shown using demand functions (30) and the property of their associated revenue functions$$
R_{j}^{i}=p_{j}^{i} q_{i}=-t q_{i}<0 \text {. }
$$

${ }^{17}$ While the two results have similar intuitions, the present result is nevertheless obtained in an environment of competing airports.
}

largely expected, the other result, $d r_{i}^{R} / d n_{j}>0$, is not obvious. Here, the explanation is related to the 'number of competitors' effect: An increase in the number of firms serving at airport $j$, while holding $n_{i}$ unchanged, would increase airport $j$ 's output share in the two-airport market. ${ }^{18}$ To counter the effect, airport $i$ strategically raises the sharing proportion so as to induce its carriers to commit to greater output. This would credibly deter airport $j$ 's carriers from producing more output, which in turn improves profit of the $i^{\text {th }}$ airport-airline chain. Finally, $d r_{i}^{R} / d n<0$ for $n_{1}=n_{2} \equiv n$, indicating that as $n$ rises, the (negative) excessive-production effect dominates the number-of-competitors effect.

Like Section 3.1 (which considers one carrier at each airport) we can compare the rivalry equilibrium with the non-rivalry solution - in the present case however, each airport has multiple carriers. It can be easily calculated that the non-rivalry sharing proportions are equal to:

$$
\begin{aligned}
& r_{i}^{N}=1+\frac{w}{h}-\frac{\left(n_{i}-1\right)(2 t+V+h-c)}{2 n_{i} h}, \\
& i=1,2 .
\end{aligned}
$$

Note, first, that if $n_{i}=1$, (39) reduces to (25) and so it extends the formula (25) to the case of multiple airlines. Second, using (39) we obtain:

$$
\frac{d r_{i}^{N}}{d n_{i}}<0, i=1,2 \text {, }
$$

that is, as the number of firms at a single airport increases and hence (uncoordinated) production gets increasingly excessive, the airport then has a greater incentive to curb production by using a smaller sharing proportion. This result is a clear extension of Proposition 1 which considers the effect of moving from one carrier to two carriers. Finally, comparing (39) with (38) yields that $r_{i}^{R}>r_{i}^{N}$ for any $n_{i}$ and $n_{j} \quad\left(n_{i}\right.$ and $n_{j}$ can take different values, $i, j=1,2$ ): i.e., the revenue-sharing proportions are greater at the rivalry revenue-sharing equilibrium than under the non-rivalry revenue-sharing solution. This extends Proposition 3 of Section 3.1 to the general case of multiple airports with each having an arbitrary number of carriers. ${ }^{19}$

\footnotetext{
18 This 'number of competitors' effect is related to a well-known result found by Salant et al. (1983): in a Cournot market, a merger of two firms into one entity reduces the merger partners' profit (unless the merger leads to a monopoly). By internalizing part of the effect that a firm's quantity decision has on the rivals' profit, the merged entity sets its quantity too low, thereby yielding market share to the non-participating firms.

19 Similarly, Proposition 4 (including the Prisoners' Dilemma result) can be extended to the $n$-carrier case. The derivation is
} 
4. Pure Revenue-Sharing Contract

So far our approach to revenue sharing has focused on a 'two part' scheme under which an airport chooses both a sharing proportion and a lump-sum fee on its carriers for the right to share concession revenue. While desirable for the airport-airlines channel as a whole, such a fixed payment between the airport and airlines may not be feasible in practice, owing, e.g., to the difficulty in their agreeing to the right amount of payment.

In this section we consider a 'pure' sharing contract under which the fixed fee is constrained to zero, while keeping the rest part of the model unchanged. Using 'hat' to denote the pure revenue-sharing equilibrium - i.e., $\left(\hat{r}_{1}, \hat{r}_{2}\right)$ - these sharing proportions are constrained by the carriers' participation constraints. Unlike the two-part sharing scheme, therefore, negative revenue sharing is not possible since these carriers cannot be compensated for with any fixed payments by the airport, indicating $\hat{r}_{i} \geq 0$. Given these observations, the effects of the pure revenue-sharing contract will be compared to those of the two-part scheme as well as the no-sharing regime.

\subsection{Single airport}

Consider first a single airport served by two carriers, which provide complementary, independent or substitutable services. The airport offers carrier $i$ a pure sharing contract with sharing proportion $r_{i}$. Each carrier's profit is given by

$$
\begin{aligned}
& \pi^{i}\left(q_{1}, q_{2}\right)=R^{i}\left(q_{1}, q_{2}\right)-C_{i}\left(q_{i}\right)-w q_{i}+r_{i} h q_{i}, \\
& i=1,2 .
\end{aligned}
$$

The stage-2 equilibrium quantities are characterized by (5), and are expressed as $q_{i}^{*}\left(r_{1}, r_{2}\right)$ with $\partial q_{i}^{*} / \partial r_{i}$ and $\partial q_{j}^{*} / \partial r_{i}$ given by (6). Then, the airport's profit in stage 1 is

$\Pi\left(r_{1}, r_{2}\right)=w \cdot\left(q_{1}^{*}+q_{2}^{*}\right)+\left(1-r_{1}\right) h q^{*}+\left(1-r_{2}\right) h q_{2}^{*} \cdot(42)$

The pure revenue-sharing equilibrium is determined, implicitly, by first-order conditions,

$$
\begin{aligned}
& \partial \Pi / \partial r_{1}=\left[w+\left(1-r_{1}\right) h\right] \cdot\left(\partial q_{1}^{*} / \partial r_{1}\right) \\
& +\left[w+\left(1-r_{2}\right) h\right] \cdot\left(\partial q_{2}^{*} / \partial r_{1}\right)-h q_{1}^{*}=0 \\
& \partial \Pi / \partial r_{2}=\left[w+\left(1-r_{2}\right) h\right] \cdot\left(\partial q_{2}^{*} / \partial r_{2}\right) \\
& +\left[w+\left(1-r_{1}\right) h\right] \cdot\left(\partial q_{1}^{*} / \partial r_{2}\right)-h q_{2}^{*}=0 \\
& \quad \text { Multiplying (43.1) by } \partial q_{1}^{*} / \partial r_{2} \text { and then }
\end{aligned}
$$

available upon request. subtracting $(43.2) \times \partial q_{1}^{*} / \partial r_{1}$ yields:

$$
\begin{aligned}
& {\left[w+\left(1-r_{2}\right) h\right]\left[\left(\partial q_{1}^{*} / \partial r_{2}\right)\left(\partial q_{2}^{*} / \partial r_{1}\right)\right.} \\
& \left.-\left(\partial q_{1}^{*} / \partial r_{1}\right)\left(\partial q_{2}^{*} / \partial r_{2}\right)\right] \\
& =h\left[q_{1}^{*}\left(\partial q_{1}^{*} / \partial r_{2}\right)-q_{2}^{*}\left(\partial q_{1}^{*} / \partial r_{1}\right)\right] . \\
& {\left[w+\left(1-r_{2}\right) h\right]\left[\left(\partial q_{1}^{*} / \partial r_{2}\right)\left(\partial q_{2}^{*} / \partial r_{1}\right)\right.} \\
& \left.-\left(\partial q_{1}^{*} / \partial r_{1}\right)\left(\partial q_{2}^{*} / \partial r_{2}\right)\right] \\
& =h\left[q_{1}^{*}\left(\partial q_{1}^{*} / \partial r_{2}\right)-q_{2}^{*}\left(\partial q_{1}^{*} / \partial r_{1}\right)\right] .
\end{aligned}
$$

Further, by (6) we have

$$
\begin{aligned}
& {\left[w+\left(1-r_{2}\right) h\right]\left[h^{2}\left(\pi_{12}^{1} \pi_{21}^{2}-\pi_{11}^{1} \pi_{22}^{2}\right) / J\right]} \\
& =h\left[q_{1}^{*}\left(\partial q_{1}^{*} / \partial r_{2}\right)-q_{2}^{*}\left(\partial q_{1}^{*} / \partial r_{1}\right)\right]
\end{aligned}
$$

Since $\pi_{12}^{1} \pi_{21}^{2}-\pi_{11}^{1} \pi_{22}^{2}=-J$, it follows that

$\left[w+\left(1-r_{2}\right) h\right] h=-\left[q_{1}^{*}\left(\partial q_{1}^{*} / \partial r_{2}\right)-q_{2}^{*}\left(\partial q_{1}^{*} / \partial r_{1}\right)\right]$

By Lemma 1 ,

$$
\partial q_{1}^{*} / \partial r_{1}>0 \text { and } \partial q_{1}^{*} / \partial r_{2}=0 \text { and }<0
$$

for independent and substitutable services respectively, we must have $w+\left(1-r_{2}\right) h>0$. Similarly, it can be shown that $w+\left(1-r_{1}\right) h>0$ for independent and substitutable services. Therefore,

$$
\begin{gathered}
\hat{r}_{i}^{I}<1+(w / h) \quad \text { and } \quad \hat{r}_{i}^{S}<1+(w / h), \\
i=1,2 .
\end{gathered}
$$

For complements however, we need to assume the symmetry condition. Under symmetry, we have $w+\left(1-r_{1}\right) h=w+\left(1-r_{2}\right) h$ in (43.1), which reduces to:

$\left[w+\left(1-r_{1}\right) h\right] \cdot\left(\partial q_{1}^{*} / \partial r_{1}+\partial q_{2}^{*} / \partial r_{1}\right)=h q_{1}^{*}$.

Because $\partial q_{1}^{*} / \partial r_{1}>0$, and $\partial q_{1}^{*} / \partial r_{2}>0$ for complementary services, we must have $w+\left(1-r_{1}\right) h>0$, and so

$\hat{r}_{i}^{C}<1+(w / h), \quad i=1,2$.

Proposition 6. At the pure revenue-sharing equilibrium with a single airport,

1. when carriers provide independent and complementary services (assuming symmetric carriers in the case of complements), both the sharing proportions and social welfare are smaller than at the two-part revenue-sharing equilibrium;

2. when carriers provide substitutable services, both the sharing proportions and social welfare may be higher or smaller than at the two-part revenue-sharing equilibrium.

The proof is relatively straightforward and is available upon request from the authors. For the 
cases of independent or complementary services, the airport, being unable to charge the fixed fee under the pure revenue sharing, shares less concession revenue with its carriers than would be under the two-part revenue sharing. This result follows directly from comparing (44)-(45) with the sharing proportions (12) and (15). This reduction in sharing will, by similar arguments used in the proof of Proposition 2, reduce social welfare.

For the substitutes case however, although the equilibrium sharing proportions are, by (44) and (16), less than $1+(w / h)$ for both types of revenue sharing, the sharing-proportions comparison between the two types is in general ambiguous. In particular, as indicated, while negative sharing is ruled out under the pure revenue sharing, it is possible under the two-part revenue sharing. In such situations, it can be shown that the pure revenue sharing results in not only a higher sharing proportion, but also a higher welfare level if carriers are sufficiently symmetric, than the two-part revenue sharing.

When competing carriers are asymmetric, however, there is an interesting twist introduced in the sharing-proportions and welfare comparison between the pure and two-part sharing arrangement. To illustrate the effect, numerical simulations are called upon. More specifically, the demands are specified as linear: $p^{i}=1-b_{i} q_{i}-k q_{j}$ with the usual properties of $b_{i}>0$ and $b_{1}, b_{2}>k$. Carrier asymmetry is introduced via (i) $b_{1} \neq b_{2}$ and/or (ii) $c_{1} \neq c_{2}$. Without loss of generality, (i) we set $b_{2}=\left(b_{1}+k\right) / 2$ and so $b_{1}>b_{2}(>k)$; and (ii) we fix $C_{2}$ and let $C_{1}$ vary. The results are given in Figure 3.

- The horizontal axis corresponds to airline 1's marginal cost $C_{1} \in[0.25,0.7]$

- - Solid Line: Results with the two-part revenue sharing

- $\quad \cdots$ Dotted Line: Results with the pure revenue sharing.

As shown in Figure 3, when firm 1 becomes more competitive (smaller $c_{1}$ ), an airport with the two-part revenue sharing will share more revenue with this carrier, while reducing the proportion shared with the other carrier (firm 2, not shown in Figure 3). By further strengthening the increasingly efficient carrier's competitiveness with a higher revenue share, and hence greater profit could be generated in the airline market, the airport would capture greater profit via the fixed transfer payment. This is not the case for the pure revenue sharing.
Under the pure revenue sharing, an airport is more concerned with total traffic volume, which determines its profit margin, and wants to stimulate the traffic with minimum revenue shared (recall that the transfer-payment device is no longer available). This implies that price elasticities of demand play a very important role in the pure revenue sharing. In particular, increasing the sharing proportion for a carrier with large market share and output (as a result of its competitiveness) would likely be more costly than doing so with a fringe carrier. As can be seen from the figure, an airport under the pure revenue sharing shares less with firm 1 as it becomes more competitive. While carrier 1's output may be higher or lower under the two-part revenue sharing than under the pure revenue sharing, total output and hence welfare are, at least for the parameter values used in Figure 3, higher under the former than the latter (note that here, the relevant range of comparison is for $\hat{r}_{i} \geq 0$ ). This is because, when competing carriers are asymmetric in costs and demands, an airport under the two-part revenue sharing has a tendency to influence the market equilibrium toward the efficient direction, which enhances social welfare.

Finally, the pure revenue sharing can also be compared to the no-sharing regime. It can be shown that at the pure revenue-sharing equilibrium, prices are lower, and both outputs and welfare are greater, than in the absence of revenue sharing. These results hold irrespective of the carriers' producing complementary, unrelated or substitutable services. The proofs are analogous to the proofs of Proposition 2, with some of the results requiring that carriers be reasonably symmetric.

\subsection{Competing airports}

Next consider two competing airports, each served by one carrier. The stage- 2 equilibrium quantities are again characterized by (5) and are given by $q_{i}^{*}\left(r_{1}, r_{2}\right)$, which have comparative-static property $\partial q_{i}^{*} / \partial r_{i}>0, i=1,2$. Then each airport's profit in stage 1 is $\Pi^{i}\left(r_{1}, r_{2}\right)=w q_{i}^{*}\left(r_{1}, r_{2}\right)+\left(1-r_{i}\right) h q_{i}^{*}\left(r_{1}, r_{2}\right)$, and the pure revenue-sharing equilibrium is characterized by first-order conditions,

$$
\begin{aligned}
& \Pi_{i}^{i}=\left[w+\left(1-r_{i}\right) h\right] \cdot\left(\partial q_{i}^{*} / \partial r_{i}\right)-h q_{i}^{*}=0, \\
& i=1,2 .
\end{aligned}
$$

From (46) and $\partial q_{i}^{*} / \partial r_{i}>0$, it follows that $w+\left(1-r_{i}\right) h>0$ and so

$0 \leq \hat{r}_{i}<1+(w / h)=r_{i}^{N}<r_{i}^{R}, i=1,2$. 
The following results are then obtained (part 2's proof is analogous to Proposition 2's):

Proposition 7. At the pure revenue-sharing equilibrium with competing airports,

1. the sharing proportions are smaller (greater, respectively) than at the two-part revenue-sharing equilibrium; and

2. under symmetry, (i) outputs and welfare are smaller (greater, respectively) and (ii) prices are higher (lower, respectively) than at the two-part revenue-sharing equilibrium (the no-sharing equilibrium, respectively).

Proposition 7 indicates that under airport competition, the pure revenue sharing improves social welfare relative to the no-sharing regime, albeit less effective than the two-part revenue sharing. In general, in terms of airfare, traffic volume and social welfare, the pure revenue sharing with competing airports lies in between the no-sharing and two-part revenue sharing regimes. It is also worth noting that unlike the ambiguous result for the single airport, the pure revenue sharing unambiguously entails a smaller sharing proportion than the two-part revenue sharing.

\section{Concluding Remarks}

This paper has investigated the implications of concession revenue sharing between an airport and its airlines. Earlier studies show that such sharing allows an airport to internalize the demand complementarity between flights and concessions, and may improve both the profit and social welfare. We found that the degree of sharing will be further affected by how carriers' services are related (complements, independent, or substitutes). In particular, when carriers provide substitutable services, the sharing proportions might become negative if horizontal substitutability is sufficiently strong and the fixed (transfer) payments between the airport and carriers are feasible (the two-part revenue sharing). The negative sharing allows the airport to penalize the over-competing airlines so as to support prices in the output market and improve profit. In these situations, while revenue sharing improves the total airport-airlines channel profit, it reduces social welfare. If the fixed payments are not feasible, under the resulting pure revenue sharing the airport will, for the cases of independent or complementary services, share less concession revenue with its carriers than would be under the two-part revenue sharing. For the substitutes case however, the sharing-proportions comparison between the two types is in general ambiguous. In the special case of negative sharing, the pure revenue sharing results in not only a higher sharing proportion, but also a higher welfare level if carriers are sufficiently symmetric, than the two-part revenue sharing. We further found that carrier asymmetry tends to favor the two-part revenue sharing, in terms of enhancing welfare, over the pure revenue sharing.

Our second objective in writing this paper is to extend the existing literature on airport-airline vertical cooperation to the general case of multiple competing airports with each having an arbitrary number of carriers. We found that airport competition will result in a higher degree of revenue sharing than would be had in the case of single airports. Nevertheless, the airport-airline chains may derive lower profits through this revenue-sharing rivalry: in effect, the airports are trapped by the incentive structure of the environment, and the situation is similar to a classic Prisoners' Dilemma. As the airport-airline chains move further away from their joint profit maximum, social welfare rises beyond the level achievable by single airports. Our analysis also showed that the (equilibrium) revenue-sharing proportion at an airport decreases in the number of its carriers, and increases in the number of carriers at the competing airport. Airline market structure will therefore influence revenue sharing arrangements not only at the airport in question, but also at the competing airports.

\section{References}

[1] ATRS (Air Transport Research Society), 2008. The ATRS Airport Performance Benchmarking Report: Global Standards for Airport Excellence, 3-volume report, published by the Centre for Transportation Studies, University of British Columbia, Vancouver, BC. www.atrsworld.org

[2] Auerbach, S. and Koch, B., 2007. Cooperative approaches to managing air traffic efficiently the airline perspective. Journal of Air Transport Management, 13, 37-44.

[3] Barbot, C., 2006. Low-cost airlines, secondary airports, and state aid: An economic assessment of the Ryanair-Charleroi airport agreement. Journal of Air Transport Management, 12, 197-203.

[4] Barbot, C., 2009a. Airport and airline competition: Incentives for vertical collusion. Transportation Research Part B (Methodological), forthcoming.

[5] Barbot, C., 2009b. Vertical contracts between airports and airlines: Is there a trade-off between welfare and competitiveness? Manuscript, CETE, Faculty of Economics of Porto, Porto, Portugal.

[6] Basso, L.J., 2008. Airport deregulation: Effects on pricing and capacity. International 
Journal of Industrial Organization, 26, 1015-1031.

[7] Basso, L.J. and Zhang, A., 2007. Congestible facility rivalry in vertical structures. Journal of Urban Economics. 61, 218-237.

[8] Brander, J.A. and Zhang, A., 1990. Market conduct in the airline industry: An empirical investigation. Rand Journal of Economics. 21, 567-583.

[9] Brander, J.A. and Zhang, A., 1993. Dynamic behaviour in the airline industry. International Journal of Industrial Organization, 11, 407-435.

[10] Brueckner, J.K., 2001. The economics of international codesharing: An analysis of airline alliances. International Journal of Industrial Organization, 19, 1475-1498.

[11] Brueckner, J.K., 2002. Airport congestion when carriers have market power. American Economic Review, 92, 1357-1375.

[12] Brueckner, J.K. and Whalen, W.T., 2000. The price effects of international airline alliances. Journal of Law and Economics, 43, 503-545.

[13] Bulow, J.I., Geanakoplos, J.D. and Klemperer, P.D., $1985 . \quad$ Multimarket oligopoly: Strategic substitutes and complements. Journal of Political Economy, 93, 488-511.

[14] Czerny, A.I., 2006. Price-cap regulation of airports: Single-till versus dual-till. Journal of Regulatory Economics, 30, 85-97.

[15] Dixit, A.K., 1986. Comparative statics in oligopoly. International Economic Review, 27 (1), 107-122.

[16] Doganis, R., 1992. The Airport Business. Routledge, London.

[17] Dresner, M., Windle, R. and Yao, Y., 2002. Airport barriers to entry in the US. Journal of Transport Economics and Policy, 36, 389-405.

[18] FAA (US Federal Aviation Administration), 1999. Airport business practices and their impact on airline competition. FAA/OST Taskforce Study.

[19] Fournier, G.M., Hartmann, M.E. and Zuehlke, T., 2007. Airport substitution by travelers: Why do we have to drive to fly? in: D. Lee (Ed.), Advances in Airline Economics, Vol. 2, pp. 209-233, Elsevier.
[20] Francis, G., Humphreys, I. and Ison, S., 2004. Airports' perspectives on the growth of low-cost airlines and the remodeling of the airport-airline relationship. Tourism Management, 25, 507-514.

[21] Friedman, J.W., 1977. Oligopoly and the Theory of Games, North Holland, Amsterdam.

[22] Fu, X. and Zhang, A., 2009. Effects of airport concession revenue sharing on competition and social welfare. Journal of Transport Economics and Policy, forthcoming.

[23] GAO (US General Accounting Office), 1997. Domestic Aviation: Barriers Continue to Limit Competition, GAO/T-RCED-98-32.

[24] Gillen, D.W. and Morrison, W.G., 2003. Bundling, integration and the delivered price of air travel: Are low cost carriers full service competitors? Journal of Air transport Management, 9, 15-23.

[25] Hartmann, M.E., 2006. Access to airport facilities: Its impact on market competition. in: D. Lee (Ed.), Advances in Airline Economics, Vol. 1, pp. 369-384, Elsevier.

[26] Ishii, J., Jun, S. and Van Dender, K., 2009. Air travel choices in multi-airport markets. Journal of Urban Economics, 65, 216-227.

[27] Jones, I., Viehoff, I. and Marks, P., 1993. The economics of airport slots. Fiscal Studies, 14, 37-57.

[28] Kuchinke, A.B. and Sickmann, J., 2005. The joint venture terminal 2 at Munich airport and the consequences: A competition economic analysis. Paper presented at the 4th Conference on Applied Infrastructure Research, Berlin, 8 October 2005.

[29] Oum, T.H., Zhang, A. and Zhang, Y., 2004. Alternative forms of economic regulation and their efficiency implications for airports. Journal of Transport Economics and Policy, 28, 217-246.

[30] Pels, E., Nijkamp, P. and Rietveld, P., 2000. Airport and airline competition for passengers departing from a large metropolitan area. Journal of Urban Economics, 48, 29-45.

[31] Pels, E., Nijkamp, P. and Rietveld, P., 2001. Airport and airline choice in a multiple airport region: An empirical analysis for the San Francisco Bay area. Regional Studies, 35, 1-9. 
[32] Pels, E., Nijkamp, P. and Rietveld, P., 2003. Access to a competition between airports: A case study for the San Francisco Bay Area. Transportation Research Part A, 37, 71-83.

[33] Pels, E. and Verhoef, E.T., 2004. The economics of airport congestion pricing. Journal of Urban Economics, 55, 257-277.

[34] Salant, S., Switzer, S. and Reynolds, R., 1983. Losses from horizontal mergers: The effects of an exogenous change in industry structure on Cournot-Nash equilibrium. Quarterly Journal of Economics, 48, 185-199.

[35] Starkie, D., 2001. Reforming UK airport regulation. Journal of Transport Economics and Policy, 35,119-135.

[36] Starkie, D., 2008. The airport industry in a competitive environment: A United Kingdom perspective. OECD-ITF Discussion Paper No. 2008-15, July 2008.
[37] Tirole, J., 1988. The Theory of Industrial Organization, MIT Press, Cambridge, Massachusetts.

[38] Zhang, A. and Zhang, Y., 1997. Concession revenue and optimal airport pricing. Transportation Research Part E, 33, 287-296.

[39] Zhang, A. and Zhang, Y., 2003. Airport charges and capacity expansion: Effects of concessions and privatization. Journal of Urban Economics, $53,54-75$.

[40] Zhang, A. and Zhang, Y., 2006. Airport capacity and congestion when carriers have market power. Journal of Urban Economics, 60, 229-247.

[41] Zhang, A., Hanaoka, S., Inamura, H. and Ishikura, T., 2009. Low cost carriers in Asia: Deregulation, regional liberalization and secondary airports. Research in Transport Economics, 24, 36-50. 

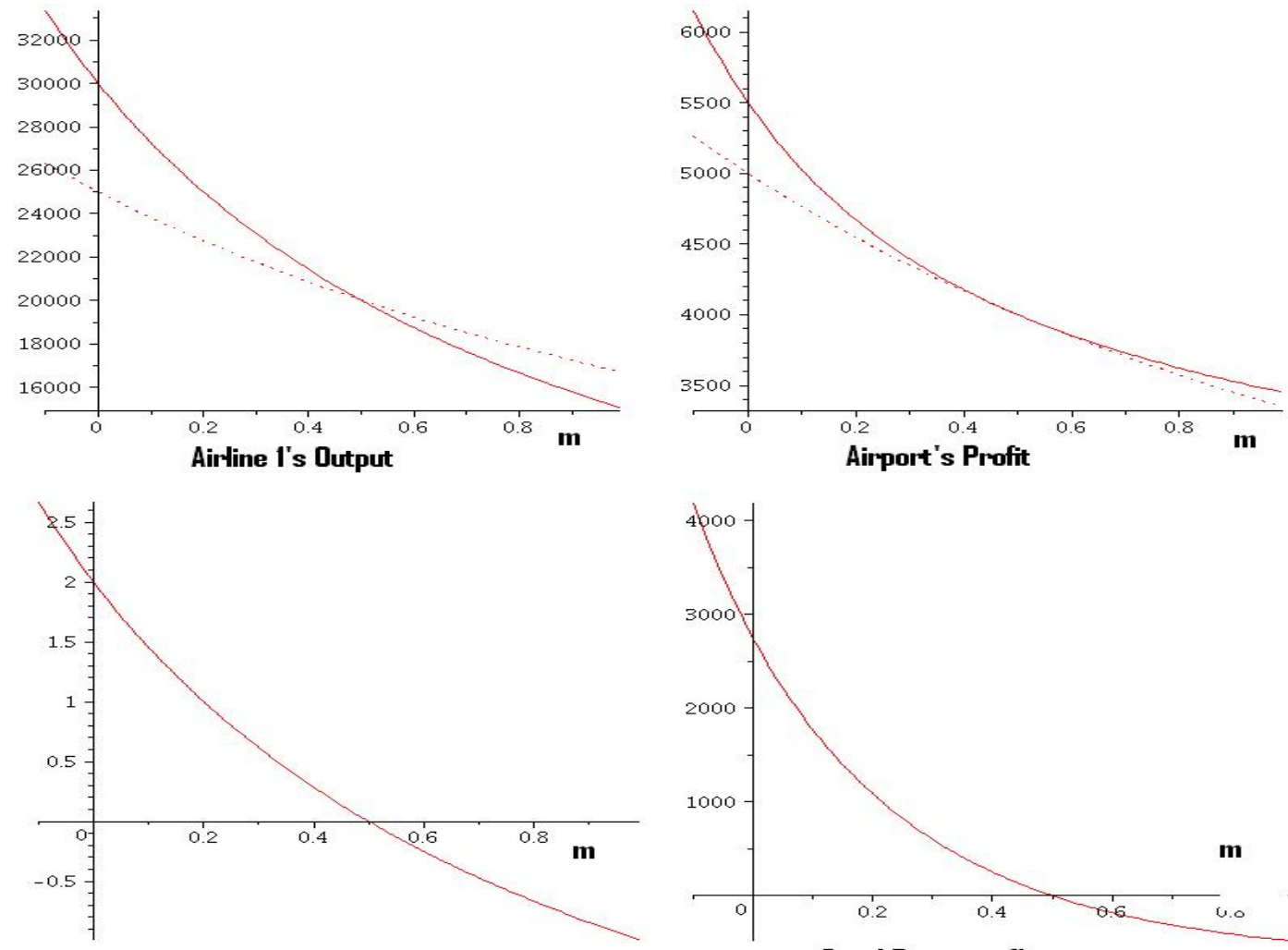

Proporition of Revenue Shared rI

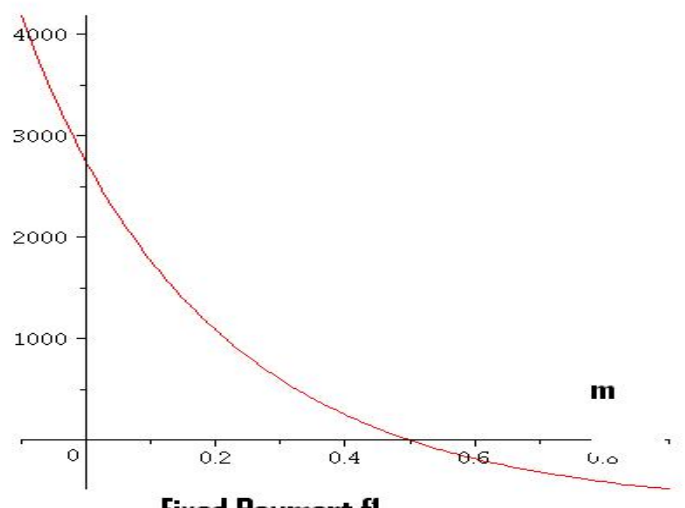

Fixed Payment f1

Figure 1. Revenue sharing vs. no sharing: Single airport with two carriers

(Parameter values: $b=0.00001, c_{1}=c_{2}=0.45, w=0.05, h=0.05$ )

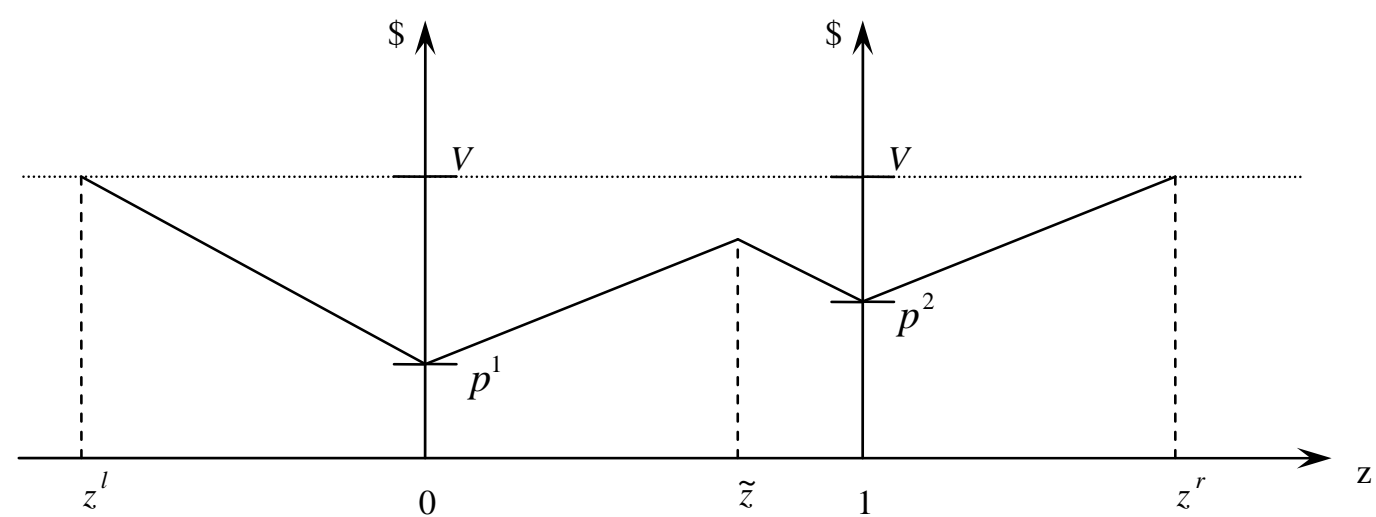

Figure 2. Consumer distribution and airports' 

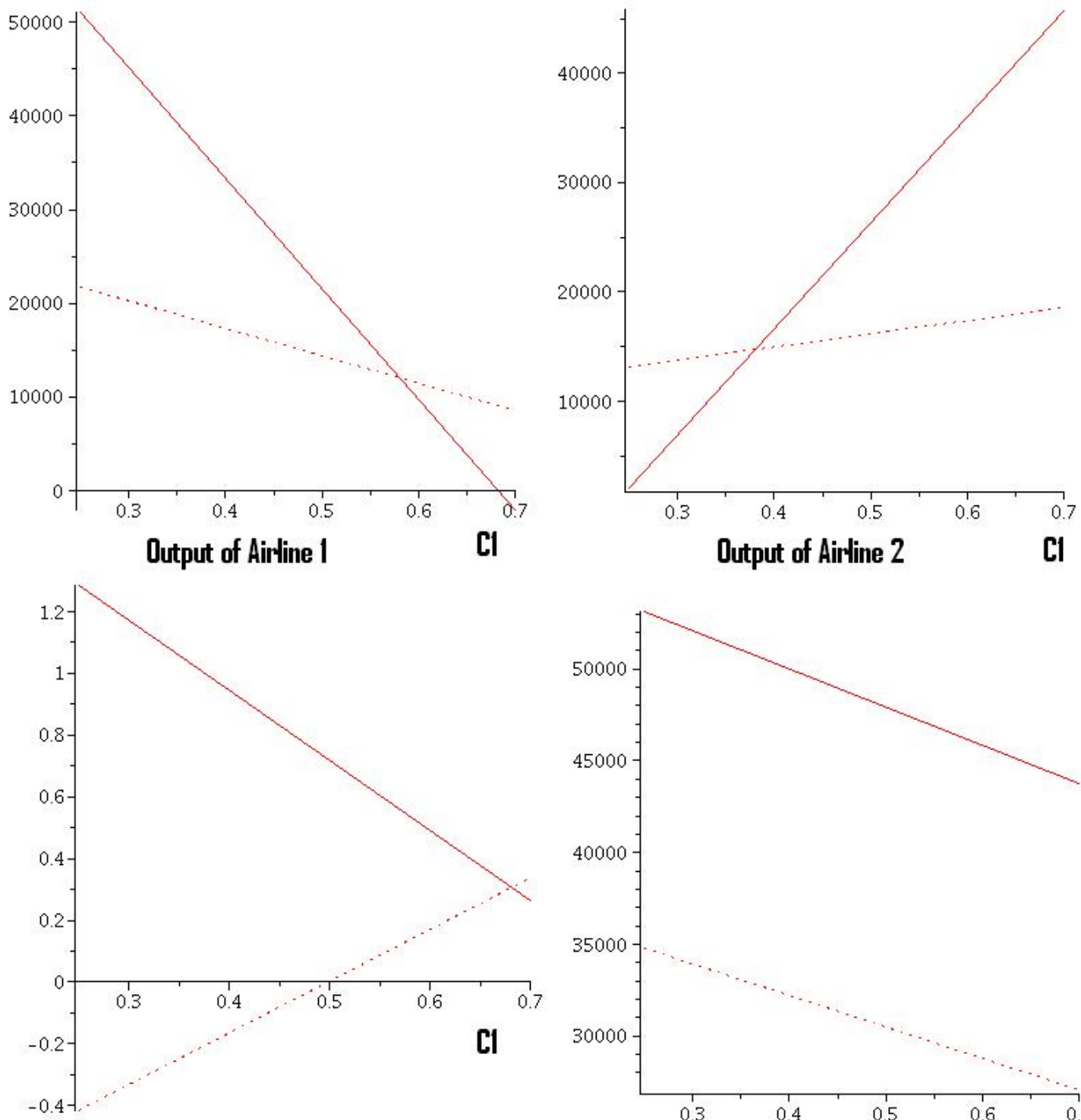

Proportions of Revenue Shared il

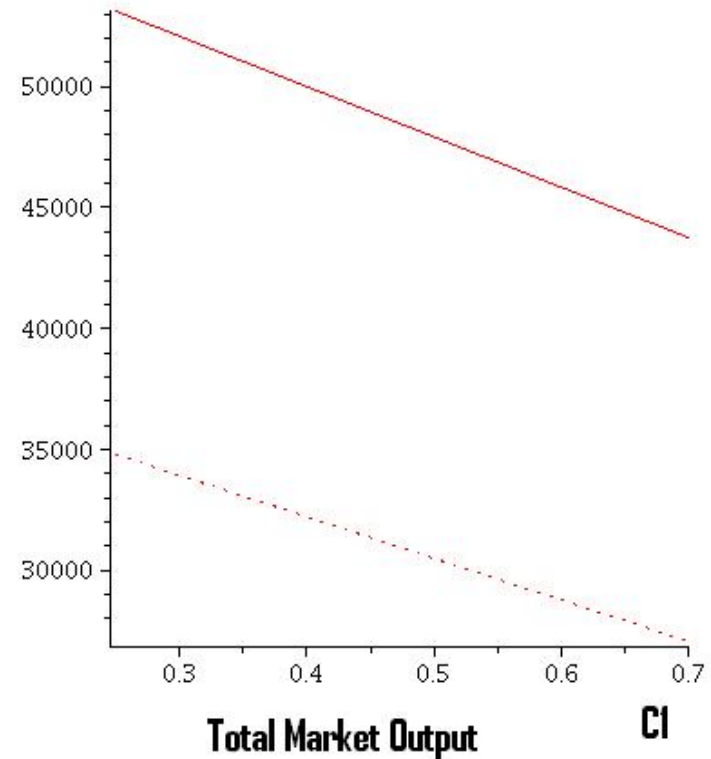

Figure 3. Two-part revenue sharing vs. pure revenue sharing: Single airport with two carriers (Parameter values: $b_{1}=0.00001, b_{2}=0.000085, k=0.00007, c_{2}=0.55, w=0.1, h=0.3$ ) 